ARTICLE

\title{
A metal-free electrocatalyst for carbon dioxide reduction to multi-carbon hydrocarbons and oxygenates
}

Jingjie $\mathrm{Wu}^{1, \star}$, Sichao $\mathrm{Ma}^{2,3, \star}$, Jing Sun ${ }^{4, \star}$, Jake I. Gold ${ }^{2}$, ChandraSekhar Tiwary ${ }^{1}$, Byoungsu Kim²,3, Lingyang Zhu ${ }^{2}$ Nitin Chopra ${ }^{5}$, Ihab N. Odeh ${ }^{5}$, Robert Vajtai ${ }^{1}$, Aaron Z. Yu ${ }^{2}$, Raymond Luo ${ }^{2}$, Jun Lou ${ }^{1}$, Guqiao Ding ${ }^{4}$, Paul J.A. Kenis ${ }^{2,3} \&$ Pulickel M. Ajayan ${ }^{1}$

Electroreduction of carbon dioxide into higher-energy liquid fuels and chemicals is a promising but challenging renewable energy conversion technology. Among the electrocatalysts screened so far for carbon dioxide reduction, which includes metals, alloys, organometallics, layered materials and carbon nanostructures, only copper exhibits selectivity towards formation of hydrocarbons and multi-carbon oxygenates at fairly high efficiencies, whereas most others favour production of carbon monoxide or formate. Here we report that nanometre-size $\mathrm{N}$-doped graphene quantum dots (NGQDs) catalyse the electrochemical reduction of carbon dioxide into multi-carbon hydrocarbons and oxygenates at high Faradaic efficiencies, high current densities and low overpotentials. The NGQDs show a high total Faradaic efficiency of carbon dioxide reduction of up to $90 \%$, with selectivity for ethylene and ethanol conversions reaching 45\%. The C2 and C3 product distribution and production rate for NGQD-catalysed carbon dioxide reduction is comparable to those obtained with copper nanoparticle-based electrocatalysts.

\footnotetext{
${ }^{1}$ Department of Materials Science and NanoEngineering, Rice University, 6100 Main Street, Houston, Texas 77005, USA. ${ }^{2}$ School of Chemical Sciences, University of IIlinois at Urbana-Champaign, Urbana, Illinois 61801, USA. ${ }^{3}$ International Institute for Carbon-Neutral Energy Research (WPI-I2CNER), Kyushu University, 744 Moto-oka, Nishi-ku, Fukuoka 819-0395, Japan. ${ }^{4}$ State Key Laboratory of Functional Materials for Informatics, Shanghai Institute of Microsystem and Information Technology, Chinese Academy of Sciences, Shanghai 200050, China. ${ }^{5}$ Saudi Basic Industries Corporation (SABIC),

Sugar Land, Texas 77478, USA. * These authors contributed equally to this work. Correspondence and requests for materials should be addressed to G.D. (email: gqding@mail.sim.ac.cn) or to P.J.A.K. (email: kenis@illinois.edu) or to P.M.A. (email: ajayan@rice.edu).
} 
E ectroreduction of carbon dioxide $\left(\mathrm{CO}_{2}\right)$ with protons from water into valued commodity chemicals offers a potential route towards a carbon-neutral society ${ }^{1}$. However, the development of this technology is hampered by the lack of active catalysts converting $\mathrm{CO}_{2}$ into more-energy embedded fuels or useful chemicals. Most metallic catalysts prefer the competitive off-pathway reduction of water to hydrogen, whereas others such as $\mathrm{Au}, \mathrm{Ag}, \mathrm{Pb}$ and $\mathrm{Sn}$ primarily catalyse production of carbon monoxide $(\mathrm{CO})$ or formate $\left(\mathrm{HCOO}^{-}\right)$via a two-electron transfer pathway ${ }^{2,3}$. On the other hand, organometallic, two-dimensional materials and nitrogen (N)-doped nanostructured carbon materials in the form of few layer graphene, carbon nanotubes (CNTs) and carbon fibres have been found only capable of catalysing $\mathrm{CO}_{2}$ reduction into $\mathrm{CO}^{4-8}$. To date, among the huge amount of screened materials, only $\mathrm{Cu}$ or copper oxide-derived catalyst are known to drive the electrolysis of $\mathrm{CO}_{2}$ into lowcarbon hydrocarbons and oxygenates at fairly high Faradaic efficiencies (FEs) through a multiple-step electron transfer pathway ${ }^{9-11}$. However, the overpotentials for hydrocarbons and oxygenates production are usually high $(-0.7 \mathrm{~V})$ on most $\mathrm{Cu}$ catalysts, whereas the overall current densities are typically below $50 \mathrm{~mA} \mathrm{~cm}^{-2}$ (refs 2,11-13). Therefore, more efforts have to be devoted, to develop more powerful catalysts for efficient $\mathrm{CO}_{2}$ conversion to multi-carbon hydrocarbons and oxygenates. Reducing the structural features to sub-nanometre dimensions often significantly enhances the hydrogenation activity for metal catalysts and it even has been demonstrated to transform a non-catalytic active bulk counterpart into a highly active catalyst towards $\mathrm{CO}_{2}$ reduction ${ }^{14-17}$. Separately, the introduction of additional defects in carbon nanostructures by heteroatom doping gives rise to activity toward $\mathrm{CO}_{2}$ activation ${ }^{6-8,18,19}$.

Here we combine a high inherent defect density, achieved by tuning the dimensions and morphology of carbon nanostructure into nanometre scale, with foreign $\mathrm{N}$-doping to obtain an advanced metal-free catalyst for electroreduction of $\mathrm{CO}_{2}$ to value-added chemicals. The resulting catalyst, specifically $\mathrm{N}$-doped graphene quantum dots (NGQDs), has substantially enriched density of $\mathrm{N}$-doping defects at edge sites. These NGQDs exhibit high activity towards the electrochemical reduction of $\mathrm{CO}_{2}$ as evidenced by high reduction current densities at low overpotentials and, more importantly, they preferentially produce multi-carbon hydrocarbons and oxygenates, especially the $\mathrm{C} 2$ products ethylene $\left(\mathrm{C}_{2} \mathrm{H}_{4}\right)$ and ethanol $\left(\mathrm{C}_{2} \mathrm{H}_{5} \mathrm{OH}\right)$ at FEs comparable to those obtained using $\mathrm{Cu}$ nanoparticle-based catalysts.

\section{Results}

NGQD synthesis. To expose the edge sites and increase their density in carbon nanostructures while simultaneously introducing non-metal heteroatom dopants at the edge locations, we intended to synthesize NGQDs through exfoliating and cutting graphene oxide (GO) precursor, and in-situ $\mathrm{N}$ doping in the dimethylformamide (DMF) solvent at elevated temperature and pressure (for synthesis details, see Supplementary Methods) ${ }^{20}$. The obtained NGQDs have a thickness between 0.7 and $1.8 \mathrm{~nm}$, corresponding to one to three atomic layers (Supplementary Fig. 1), and a narrow lateral size distribution of $1-3 \mathrm{~nm}$ (Fig. 1a,b and Supplementary Fig. 1). The high-resolution transmission electron microscopy (TEM) images show the hexagonal-like morphology of NGQDs and their honeycomb framework (inset in Fig. $1 \mathrm{~b}$ showing a representative zigzag edge), indicating the preservation of the graphene crystal structure. High-resolution TEM images of NGQDs with distinguishable atoms are difficult to take, as the NGQDs are even thinner than the carbon support film in the TEM grid. We do not have a large quantity sample base to analyse the percentage of NGQDs with zigzag edges over armchair edges, but the exigence of NGQDs with armchair edges could not be excluded in our sample. Pristine GQDs, without $\mathrm{N}$-doping, were also synthesized from the same GO precursor using the identical hydrothermal analogous treatment in a solvent mixture of IPA $/ \mathrm{H}_{2} \mathrm{O}$ (1:1 by volume) instead of $\mathrm{DMF}^{21}$. The pristine GQDs exhibit a similar morphology (thickness and lateral size) as the NGQDs (Supplementary Fig. 2). The Raman spectrum of NGQDs shows the characteristic D band at $1,350 \mathrm{~cm}^{-1}$ and $G$ band at $1,589 \mathrm{~cm}^{-1}$, whereas the second order band (2D) has been quenched compared with pristine GQDs (Fig. 1c). The ratio of $I_{\mathrm{D}} / I_{\mathrm{G}}$ (D band intensity to $\mathrm{G}$ band intensity) for NGQDs is much higher than that for the pristine GQDs, due largely to the introduction of additional defects on $\mathrm{N}$ doping. The survey scan of X-ray photoelectron spectroscopy (XPS) clearly shows the presence of $\mathrm{N}$ in the NGQDs, whereas the $\mathrm{N}$ 1s peak was not observed for pristine GQDs (Supplementary Fig. 3). Analysis of the fine scan of the $\mathrm{N} 1 s$ region provides information on the specific configuration of the $\mathrm{N}$ dopants in the carbon lattice network (Fig. 1d). Deconvolution of the N $1 s$ peak reveals three peaks that can be assigned to pyridinic $(398.5 \mathrm{eV})$, pyrrolic $(400.0 \mathrm{eV})$ and graphitic $\mathrm{N}(401.2 \mathrm{eV})^{22}$. The total N content in NGQDs based on $\mathrm{N} /(\mathrm{C}+\mathrm{N})$ is around 6.0 at.\%, in which pyridinic $\mathrm{N}$ is predominant with $\sim 3.9$ at.\% (Fig. $1 \mathrm{~d}$ and Supplementary Fig. 3).

Electrocatalytic activity and selectivity towards $\mathrm{CO}_{2}$ reduction. The electrocatalytic activity and selectivity of NGQDs towards $\mathrm{CO}_{2}$ reduction were evaluated in a flow cell in which NGQDs were deposited on a gas diffusion electrode (Supplementary Fig. 4) $)^{9}$. The electrolysis was performed in an electrolyte of $1 \mathrm{M}$ $\mathrm{KOH}$ in the potentiostatic mode with cathodic potentials in the range of -0.20 to $-1.10 \mathrm{~V}$ (versus reversible hydrogen electrode (RHE)). The total FE of $\mathrm{CO}_{2}$ reduction increases as a more negative potential is applied, from $18 \%$ at $-0.26 \mathrm{~V}$ to a maximum of $90 \%$ at $-0.75 \mathrm{~V}$ and, subsequently, it declines to $64 \%$ at $-1.03 \mathrm{~V}$ (Fig. 2a). Only $\mathrm{CO}$ and $\mathrm{HCOO}^{-}$are observed at a low cathode potential of $-0.26 \mathrm{~V}$. However, when the applied potential sweeps more negatively, various hydrocarbons of methane $\left(\mathrm{CH}_{4}\right)$ and $\mathrm{C}_{2} \mathrm{H}_{4}$, and multi-carbon oxygenates including $\mathrm{C}_{2} \mathrm{H}_{5} \mathrm{OH}$, acetate $\left(\mathrm{CH}_{3} \mathrm{COO}^{-}\right)$and $n$-propanol $(n$ $\mathrm{C}_{3} \mathrm{H}_{7} \mathrm{OH}$ ) are produced in addition to $\mathrm{CO}$ and $\mathrm{HCOO}^{-}$(Fig. 2a). The fact that NGQDs favour catalysing $\mathrm{C}-\mathrm{C}$ bond formation beyond the potential of $-0.61 \mathrm{~V}$, leading to predominant production of $\mathrm{C} 2$ and $\mathrm{C} 3$ products, is striking (Fig. 2a and Supplementary Fig. 5). $\mathrm{C}_{2} \mathrm{H}_{4}$ is the major hydrocarbon product with a maximum $\mathrm{FE}$ of $31 \%$ at $-0.75 \mathrm{~V}$, whereas $\mathrm{CH}_{4}$ has a maximum $\mathrm{FE}$ of only $15 \%$ at $-0.86 \mathrm{~V}$. In addition to $\mathrm{C} 2$ hydrocarbons, another prominent feature of the NGQDs lies in its outstanding selectivity to formation of multi-carbon oxygenate liquid fuels. At $-0.78 \mathrm{~V}$, the maximum $\mathrm{FE}$ for multi-carbon oxygenates reaches $26 \%$, with the major component $\mathrm{C}_{2} \mathrm{H}_{5} \mathrm{OH}$ accounting for $16 \%$. In comparison, $\mathrm{Cu}$ nanoparticle-based catalysts yield trace $\mathrm{CH}_{4}(<1 \%)$, but comparable $\mathrm{C}_{2} \mathrm{H}_{4}(31.2 \%)$ and $\mathrm{C}_{2} \mathrm{H}_{5} \mathrm{OH}(11.8 \%)$ at the similar potential of $-0.74 \mathrm{~V}$ (Supplementary Fig. 6) ${ }^{9}$. Overall, the NGQD catalyst exhibits electrocatalytic performance towards $\mathrm{CO}_{2}$ reduction that is similar to what has been observed for $\mathrm{Cu}$ nanoparticle catalysts in terms of the $\mathrm{FE}$ for $\mathrm{C} 2$ and $\mathrm{C} 3$ products.

To verify that the $\mathrm{CO}_{2}$ reduction reaction was catalysed by NGQDs, multiple control experiments were conducted. In one control experiment, argon gas was supplied to the cathode compartment instead of $\mathrm{CO}_{2}$, which resulted in the exclusive production of hydrogen over the cathodic potential window of $-0.2 \sim-1.0 \mathrm{~V}$. In a second control experiment using a bare gas diffusion electrode as the cathode (no NGQD catalyst), 
a

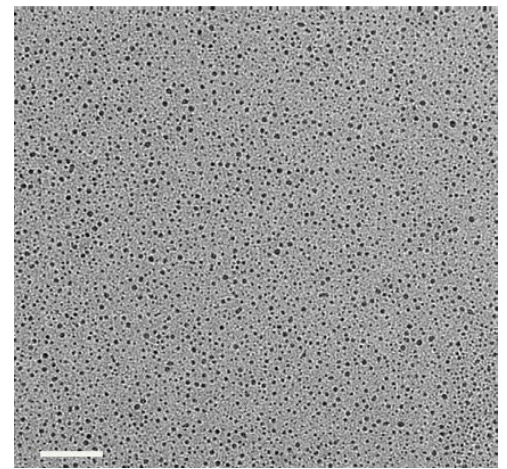

C

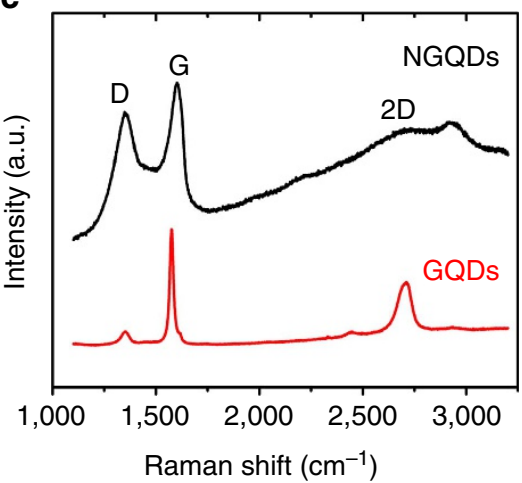

b

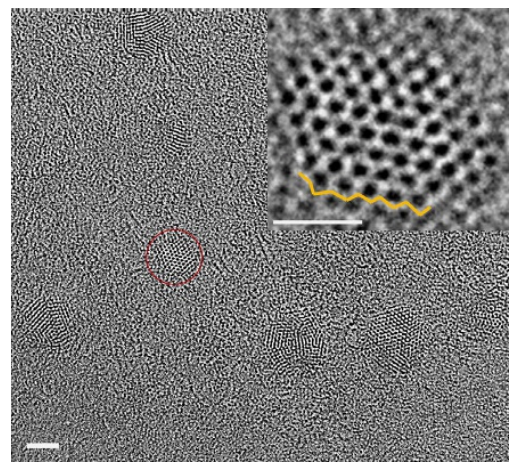

d

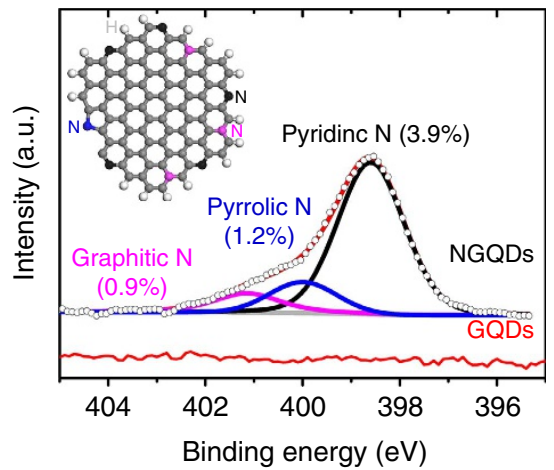

Figure 1 | Nanostructure and specific nitrogen dopant configurations of NGQDs. (a) Low-magnification TEM image of NGQDs. Scale bar, 50 nm. (b) High-magnification TEM image of NGQDs. Scale bar, $2 \mathrm{~nm}$. Inset shows a single NGQD containing zigzag edges as circled. The yellow line outlines the zigzag edge. Scale bar in inset, $1 \mathrm{~nm}$. (c) Raman spectrum of NGQDs as compared with that of pristine GQDs. (d) High-resolution $\mathrm{N}$ 1s spectrum for NGQDs, deconvoluted into three sub-peaks representing pyridinic, pyrrolic and graphitic $\mathrm{N}$. The value in parentheses is the corresponding $\mathrm{N}$ atomic concentration calculated based on $\mathrm{N} /(\mathrm{N}+\mathrm{C})$. The inset is a schematic demonstrating zigzag edges and the $\mathrm{N}$-bonding configuration with respect to pyridinic (black), pyrrolic (blue) and graphitic (pink) N. In comparison, the N 1s peak does not appear in GQDs sample.

hydrogen formation prevailed over the same potential region. Furthermore, in an experiment using an isotopically labelled ${ }^{13} \mathrm{CO}_{2}$ gas feed, mass spectrometry showed signals for ${ }^{13} \mathrm{CO}$ $(m / z=29),{ }^{13} \mathrm{CH}_{4}(m / z=17)$ and ${ }^{13} \mathrm{C}_{2} \mathrm{H}_{4}(m / z=30)$, whereas a spin doublet appeared in ${ }^{1} \mathrm{H}$ NMR due to proton coupling to ${ }^{13} \mathrm{C}$ in the liquid products (Supplementary Fig. 7), all confirming that these products are derived from ${ }^{13} \mathrm{CO}_{2}$ electroreduction. In addition, inductively coupled plasma optical emission spectroscopy revealed that the NGQDs samples only contained 1.02 p.p.m. $\mathrm{Cu}$, corresponding to a $\mathrm{Cu}$ loading of around $5 \times 10^{-3} \mu \mathrm{g} \mathrm{cm}^{-2}$ on the cathode, which is too low to catalyse $\mathrm{CO}_{2}$ reduction to hydrocarbons and oxygenates at the levels observed here, as previously reported ${ }^{23}$. These results confirm the activity of the NGQDs studied here towards efficient reduction of $\mathrm{CO}_{2}$ to multi-carbon hydrocarbons and oxygenates.

Origin of electrocatalytic activity and selectivity. To unveil the origin of the activity and selectivity of NGQDs, pristine GQDs were also tested for $\mathrm{CO}_{2}$ reduction under identical experimental conditions. The hydrogen evolution reaction dominates over the $\mathrm{CO}_{2}$ reduction reaction for the GQDs electrode. GQDs not only initialize $\mathrm{CO}_{2}$ reduction at a more negative potential, but also primarily produce $\mathrm{CO}$ and $\mathrm{HCOO}^{-}$at even lower FEs than NGQDs (Fig. 2b). Compared with NGQDs, the FEs of hydrocarbons such as $\mathrm{CH}_{4}$ and $\mathrm{C}_{2} \mathrm{H}_{4}$ observed with the GQDs are low not more than 5-6\% each. Moreover, only a trace amount of $\mathrm{CH}_{3} \mathrm{COO}^{-}$and no $\mathrm{C}_{2} \mathrm{H}_{5} \mathrm{OH}$ or $n-\mathrm{C}_{3} \mathrm{H}_{7} \mathrm{OH}$ were observed. In addition, the Tafel plots derived from the partial current density of $\mathrm{CO}_{2}$ reduction $\left(j_{\mathrm{CO}_{2}}\right.$ reduction $)$ versus cathode potential show that the GQDs electrode has a larger apparent Tafel slope than the NGQDs electrode $\left(371 \mathrm{mV} \mathrm{dec}^{-1}\right.$ for GQDs versus $198 \mathrm{mV} \mathrm{dec}^{-1}$ for NGQDs), indicating that the GQDs electrode exhibits much slower kinetics than the NGQDs electrode (Fig. 2d). This NGQDs versus GQDs performance comparison underscores the significance of the $\mathrm{N}$-doping defects in the NGQD catalyst in determining its activity. Previously, the incorporation of $\mathrm{N}$ defects to $s p^{2}$ carbon nanostructures to induce charge density was reported to be crucial for actively catalysing electrochemical reactions such as oxygen reduction reaction (ORR) ${ }^{24-26}$. Among the most common $\mathrm{N}$ configurations, pyridinic $\mathrm{N}$ is experimentally proven to create the most active site for the ORR ${ }^{27-29}$. Similar to ORR, our prior work on $\mathrm{N}$-doped CNTs and graphene suggests that pyridinic $\mathrm{N}$ is the leading active site for $\mathrm{CO}_{2}$ reduction ${ }^{6,7}$. The acidic $\mathrm{CO}_{2}$ molecule prefers adsorbing onto the Lewis basic pyridinic $\mathrm{N}$ group in carbon nanostructures ${ }^{27}$.

The NGQDs samples were analysed by ex-situ post-reaction XPS. After testing for $\mathrm{CO}_{2}$ reduction, the relative concentration of pyridinic $\mathrm{N}(398.5 \mathrm{eV})$ decreases from 65 to $38 \%$ and another $\mathrm{N}$ component with a peak of $400.0 \mathrm{eV}$ (pyrrolic or pyridonic $\mathrm{N}$ ) increases from 20 to $50 \%$, whereas the percentage of graphitic $\mathrm{N}(401.2 \mathrm{eV})$ remains relatively unchanged (from 15 to $12 \%$; Supplementary Fig. 8). The change of $\mathrm{N}$ component fraction before and after $\mathrm{CO}_{2}$ reduction measurement possibly results from the adsorption of $\mathrm{CO}_{2}$ onto the active pyridinic $\mathrm{N}$ that causes the upshift of binding energy of pyridinic $\mathrm{N}$ to a similar value of pyrrolic N. By applying potential, the adsorbed $\mathrm{CO}_{2}$ is 
a

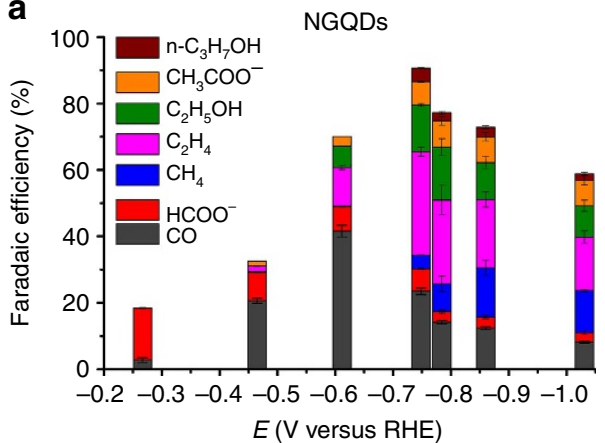

C

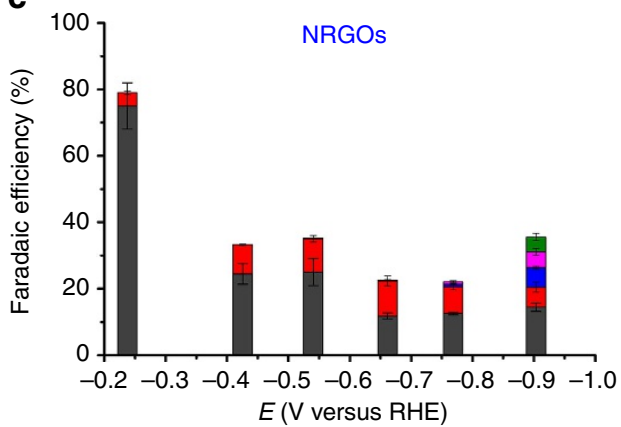

b

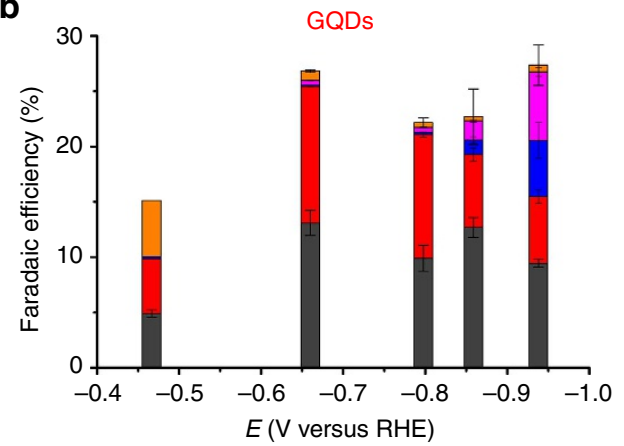

d

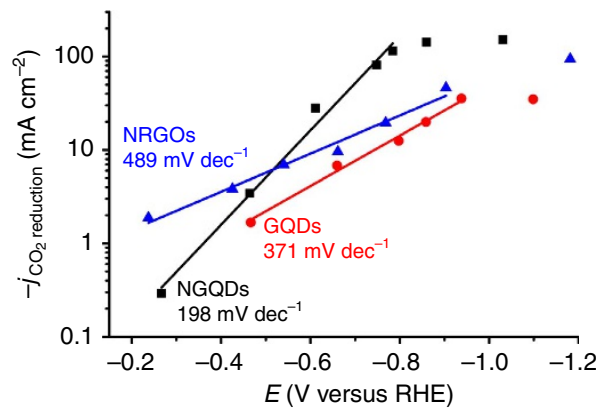

Figure 2 | Electrocatalytic activity of carbon nanostructures towards $\mathbf{C O}_{\mathbf{2}}$ reduction. (a) FEs of carbon monoxide $(\mathrm{CO})$, methane $\left(\mathrm{CH}_{4}\right)$, ethylene $\left(\mathrm{C}_{2} \mathrm{H}_{4}\right)$, formate $\left(\mathrm{HCOO}^{-}\right)$, ethanol $(\mathrm{EtOH})$, acetate $\left(\mathrm{AcO}^{-}\right)$and $n$-propanol $(n-\mathrm{PrOH})$ at various applied cathodic potential for $\mathrm{NGQDs}$. (b) FE of $\mathrm{CO}_{2}$ reduction products for pristine GQDs. (c) Selectivity to $\mathrm{CO}_{2}$ reduction products for NRGOs. (d) Tafel plots of partial current density of $\mathrm{CO}_{2}$ reduction versus applied cathodic potential for three nanostructured carbon catalysts. The error bar represents the s.d. of three separate measurements for an electrode.

a

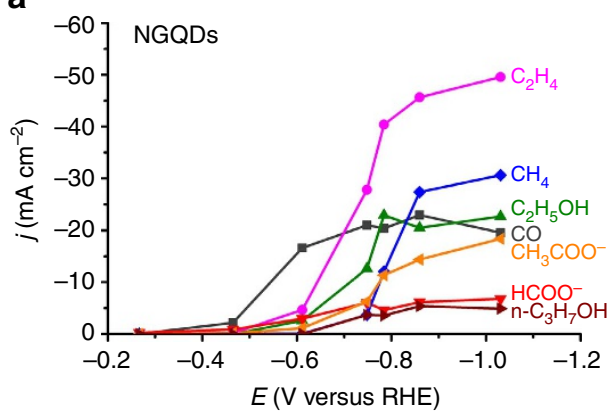

b

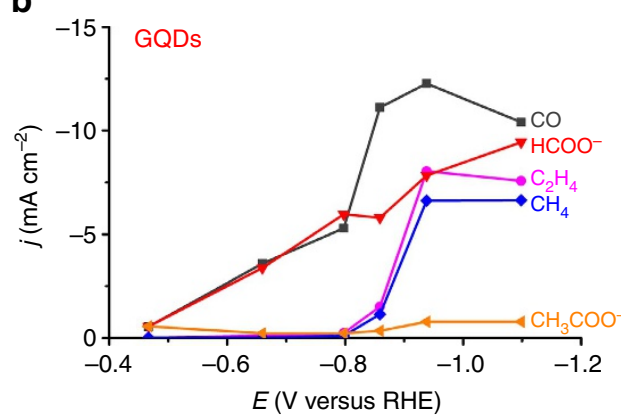

Figure 3 | Partial current densities as a function of cathode potential for various products from electrochemical $\mathrm{CO}_{2}$ reduction. (a) When using NGQDs as cathode catalyst. (b) When using GQDs as cathode catalyst.

further reduced to products that are released from the pyridinic $\mathrm{N}$ site, then the pyridinic $\mathrm{N}$ regenerates for next round of $\mathrm{CO}_{2}$ adsorption/reduction.

To further explore the active site, the $\mathrm{N}$-doped reduced GOs (NRGOs) were prepared by doping GOs with $\mathrm{NH}_{3}$ at $800^{\circ} \mathrm{C}$. The NRGOs contain a concentration of each specific $\mathrm{N}$ configuration that is similar to the distribution in NGQDs, but the NRGOs have larger micrometre-scale lateral size (Supplementary Figs 9 and 10). The onset potential for $\mathrm{CO}_{2}$ reduction on the NRGOs electrode is identical to that for the NGQDs electrode (Fig. 2a,c). However, the NRGOs electrode primarily catalyses $\mathrm{CO}_{2}$ reduction to form $\mathrm{CO}$ (Fig. 2c), similar to previously reported observations when using $\mathrm{N}$-doped graphene and $\mathrm{N}$-doped $\mathrm{CNTs}^{6,7}$. The formation of noticeable amounts of hydrocarbons $\mathrm{CH}_{4}(\sim 6 \%), \mathrm{C}_{2} \mathrm{H}_{4}(\sim 5 \%)$ and oxygenates $\mathrm{C}_{2} \mathrm{H}_{5} \mathrm{OH}(\sim 4 \%)$ starts at $-0.90 \mathrm{~V}$ on NRGOs, a significantly more negative potential than that $(-0.61 \mathrm{~V})$ on NGQDs. Compared with NRGOs, pristine RGOs exclusively catalyse the hydrogen evolution reaction, underlining the ability of $\mathrm{N}$ doping to transform carbon nanostructures from being inert to highly catalytically active. The kinetics for $\mathrm{CO}_{2}$ reduction on NRGOs is also slower than that on NGQDs, for example, a Tafel slope of $489 \mathrm{mV} \mathrm{dec}^{-1}$ for NRGOs versus $198 \mathrm{mV} \mathrm{dec}^{-1}$ for NGQDs (Fig. 2d). This comparison of NGQDs and NRGOs clearly suggests that the morphology also plays a key role in determining the activity of carbon nanostructures towards $\mathrm{CO}_{2}$ reduction in addition to doping-induced defects. When $1-3 \mu \mathrm{m}$ diameter NRGOs sheets are pulverized into $1-3 \mathrm{~nm}$ quantum dots, the density of exposed edge sites increases by three orders of magnitude: $0.05 \%$ for $1 \mu \mathrm{m}$ NRGO sheet versus $44 \%$ for $1 \mathrm{~nm}$ NGQD (Supplementary Fig. 11). Owing to the lower formation energy of $\mathrm{N}$ doping at the edge sites than the basal planes, especially for pyridinic $\mathrm{N}$, most of the $\mathrm{N}$ dopants would locate at the edge sites in NGQDs ${ }^{30,31}$. In contrast, in the case of NRGOs, $\mathrm{N}$ dopants mostly locate in the basal planes because insufficient edge sites are present to accommodate the dopants. Although 
they are similar in pyridinic $\mathrm{N}$ content, NGQDs tend to have higher density of pyridinic $\mathrm{N}$ at edge sites than NRGOs. The pyridinic $\mathrm{N}$ at the edge site is believed to be more active to induce $\mathrm{C}-\mathrm{C}$ bond formation than those at the basal plane, which leads to a higher yield of $\mathrm{C} 2$ and $\mathrm{C} 3$ products on NGQDs electrode than on NRGOs electrode ${ }^{32}$.

Production rate of $\mathrm{CO}_{2}$ reduction products. In addition to the promising selectivity with respect to the formation of multicarbon hydrocarbons and oxygenates, the NGQDs electrode also exhibits a high $\mathrm{CO}_{2}$ reduction current density of $100 \mathrm{~mA} \mathrm{~cm}^{-2}$ at relative low potentials (Supplementary Fig. 12). The partial current densities for production of $\mathrm{CO}, \mathrm{C}_{2} \mathrm{H}_{4}$ and $\mathrm{C}_{2} \mathrm{H}_{5} \mathrm{OH}$ reach 23,46 and $21 \mathrm{~mA} \mathrm{~cm}^{-2}$ at $-0.86 \mathrm{~V}$, respectively (Fig. 3a), which are on the same order of magnitude compared with corresponding partial current densities observed for commercial $\mathrm{Cu}$ nanoparticles (around $20-40 \mathrm{~nm}$ ) under identical testing conditions 9 . Accordingly, $\mathrm{CO}, \mathrm{C}_{2} \mathrm{H}_{4}$ and $\mathrm{C}_{2} \mathrm{H}_{5} \mathrm{OH}$ could be produced at rates of $4.2,1.4$ and $0.7 \mathrm{~mol} \mathrm{~h}^{-1} \mathrm{~m}^{-2}$ at $-0.86 \mathrm{~V}$, respectively (Supplementary Fig. 13). In contrast, the GQDs exhibit a partial current density or production rate for $\mathrm{C}_{2} \mathrm{H}_{4}$ that is at least one order of magnitude lower at comparable potentials (Fig. 3b and Supplementary Fig. 13).

\section{Discussion}

A metal-free catalyst comprising NGQDs is discovered to exhibit extraordinary activity towards $\mathrm{CO}_{2}$ reduction. Interestingly, NGQDs show predominant selectivity to the production of multi-carbon hydrocarbons and oxygenates, whereas GQDs and NRGOs primarily yield $\mathrm{CO}$ and $\mathrm{HCOO}^{-}$. Detailed characterization reveals that the unique nanostructure in combination with utmost exposure of edge sites and heteroatom $\mathrm{N}$ doping grants NGQDs the unprecedented activity and selectivity. This finding expands the horizon for the design of high-performance electrocatalysts for $\mathrm{CO}_{2}$ reduction. However, the reaction mechanism of electroreduction of $\mathrm{CO}_{2}$ over NGQDs remains elusive and the unravelling requires further work. The combination of high-sensitive operando spectroscopy and first-principle calculation would be an efficient way to provide insight into the reaction intermediates to reveal the reaction pathways. In addition, the activity difference between the zig-zag and armchair edge necessitates exploration as well in the future.

\section{Methods}

GQD synthesis. NGQDs were synthesized by heat treating the GO dispersion in DMF in a PTFE-lined autoclave at $200^{\circ} \mathrm{C}$ for $10 \mathrm{~h}$. The pristine GQDs were prepared in a similar way, except using a mixture of isopropanol and water (1:1 by volume) as the solvent. The NRGO was prepared by doping GO in a tube furnace at $800^{\circ} \mathrm{C}$, while flowing ammonia for $1 \mathrm{~h}$. More details about the synthesis and characterization are in the Supplementary Information.

\footnotetext{
Materials characterization. The morphology and crystallinity of N-doped and pristine GQDs was characterized by high-resolution field-emission gun TEM (JEOL 2,100 FEG TEM). The TEM samples were prepared by dropping the QDs solution onto the ultrathin carbon film TEM grid followed by vacuum drying at $100^{\circ} \mathrm{C}$. The thickness of QDs was measured by atomic force microscopy with tapping mode (Bruker Multimode 8). The atomic force microscopy samples were prepared by dropping the QDs solution onto the Mica substrate. The morphology of NRGOs was analysed by scanning electron microscope (FEI Quanta 400 FEG ESEM). The Raman spectra were taken with a Renishaw inVia Raman microscope with $514 \mathrm{~nm}$ laser excitation. XPS measurements were performed to analyse the element component and oxide state of QDs and NRGOs at ambient temperature using PHI Quantera with Al-K $\alpha$ X-ray source. The Cu content in the NGQDs was determined by using inductively coupled plasma optical emission spectroscopy (PerkinElmer-Optima 2000DV). One millilitre of original liquid sample that is dissolved in DMF was diluted with $5 \mathrm{ml}$ water, then one drop $(\sim 0.05 \mathrm{ml})$ of concentrated $\mathrm{HNO}_{3}$ was used to adjust the $\mathrm{pH}$ to be $<7$. Two different emission lines: $\lambda=224.7000 \mathrm{~nm}$ and $\lambda=213.5970 \mathrm{~nm}$ were used to detect the $\mathrm{Cu}$ element. The detection limit for $\mathrm{Cu}$ is 10 p.p.b.
}

Electrochemical measurement of $\mathbf{C O}_{\mathbf{2}}$ reduction. The $\mathrm{CO}_{2}$ reduction reaction was conducted in an electrochemical flow cell composed of targeted quantum dots or NRGO-based gas diffusion electrodes (see Supplementary Fig. 4). The electrochemical measurement was carried out at ambient pressure and temperature. The electrolysis was performed under potentiostatic mode with a full cell voltage ranging from -1.6 to $-3.5 \mathrm{~V}$ controlled by a potentiostat (Autolab PGSTAT-30, EcoChemie). Both the catholyte and anolyte were $1 \mathrm{M} \mathrm{KOH}$ ( $\mathrm{pH} 13.48$, as calibrated by a $\mathrm{pH}$ meter (Thermo Orion, 9106BNWP). Individual electrode potentials were recorded using multimeters (AMPROBE 15XP-B) connected to each electrode and a reference electrode $(\mathrm{Ag} / \mathrm{AgCl} ; \mathrm{RE}-5 \mathrm{~B}, \mathrm{BASi})$ placed in the electrolyte exit stream. The measured potentials after $\mathrm{iR}$ compensation were rescaled to the RHE by $\mathrm{E}$ (versus $\mathrm{RHE})=\mathrm{E}$ (versus $\mathrm{Ag} / \mathrm{AgCl})+0.209 \mathrm{~V}+0.0591$ $\mathrm{V} / \mathrm{pH} \times \mathrm{pH}$. The current reported here was obtained by averaging the span of time (at least $180 \mathrm{~s}$ ) for each applied voltage.

For each applied voltage, after the cell reached steady state, $1 \mathrm{ml}$ of the effluent gas stream was periodically sampled and diverted into a gas chromatograph (Thermo Finnegan Trace GC) equipped with both the thermal conductivity and flame ionization detector, and a Carboxen 1,000 column (Supelco). Meanwhile, the exit catholyte was collected at each applied voltage followed by identifying and quantifying using ${ }^{1} \mathrm{H}$ NMR (nuclear magnetic resonance, UI500NB, Varian).

Data availability. The data that support the findings of this study are available from the corresponding author upon request.

\section{References}

1. Whipple, D. T. \& Kenis, P. J. A. Prospects of $\mathrm{CO}_{2}$ utilization via direct heterogeneous electrochemical reduction. J. Phys. Chem. Lett. 1, 3451-3458 (2010).

2. Hori, Y., Wakebe, H., Tsukamoto, T. \& Koga, O. Electrocatalytic process of CO selectivity in electrochemical reduction of $\mathrm{CO}_{2}$ at metal electrodes in aqueous media. Electrochim. Acta 39, 1833-1839 (1994).

3. Qiao, J., Liu, Y., Hong, F. \& Zhang, J. A review of catalysts for the electroreduction of carbon dioxide to produce low-carbon fuels. Chem. Soc. Rev. 43, 631-675 (2014).

4. Lin, S. et al. Covalent organic frameworks comprising cobalt porphyrins for catalytic $\mathrm{CO}_{2}$ reduction in water. Science 349, 1208-1213 (2015).

5. Asadi, M. et al. Robust carbon dioxide reduction on molybdenum disulphide edges. Nat. Commun. 5, 4470 (2014).

6. Wu, J. et al. Achieving highly efficient, selective and stable $\mathrm{CO}_{2}$ reduction on nitrogen doped carbon nanotubes. ACS Nano 9, 5364-5371 (2015).

7. Wu, J. et al. Incorporation of nitrogen defects for efficient reduction of $\mathrm{CO}_{2}$ via two-electron pathway on three-dimensional graphene foam. Nano Lett. 16, 466-470 (2016).

8. Kumar, B. et al. Renewable and metal-free carbon nanofibre catalysts for carbon dioxide reduction. Nat. Commun. 4, 2819 (2013).

9. Ma, S. et al. One-step electrosynthesis of ethylene and ethanol from $\mathrm{CO}_{2}$ in an alkaline electrolyzer. J. Power Sources 301, 219-228 (2016).

10. Kuhl, K. P., Cave, E. R., Abram, D. N. \& Jaramillo, T. F. New insights into the electrochemical reduction of carbon dioxide on metallic copper surfaces. Energy Environ. Sci. 5, 7050-7059 (2012).

11. Li, C. W. \& Kanan, M. W. $\mathrm{CO}_{2}$ reduction at low overpotential on $\mathrm{Cu}$ electrodes resulting from the reduction of thick $\mathrm{Cu} 2 \mathrm{O}$ films. J. Am. Chem. Soc. 134, 7231-7234 (2012).

12. Reske, R., Mistry, H., Behafarid, F., Roldan Cuenya, B. \& Strasser, P. Particle size effects in the catalytic electroreduction of $\mathrm{CO}_{2}$ on $\mathrm{Cu}$ nanoparticles. J. Am. Chem. Soc. 136, 6978-6986 (2014).

13. Hori, Y., Murata, A. \& Takahashi, R. Formation of hydrocarbons in the electrochemical reduction of carbon dioxide at a copper electrode in aqueous solution. J. Chem. Soc. Faraday Trans. 1 85, 2309-2326 (1989).

14. Liu, C. et al. Carbon dioxide conversion to methanol over size-selected $\mathrm{Cu}_{4}$ clusters at low pressures. J. Am. Chem. Soc. 137, 8676-8679 (2015).

15. Liu, C., He, H., Zapol, P. \& Curtiss, L. A. Computational studies of electrochemical $\mathrm{CO}_{2}$ reduction on subnanometer transition metal clusters. Phys. Chem. Chem. Phys. 16, 26584-26599 (2014).

16. Gao, S. et al. Partially oxidized atomic cobalt layers for carbon dioxide electroreduction to liquid fuel. Nature 529, 68-71 (2016).

17. Kauffman, D. R., Alfonso, D., Matranga, C., Qian, H. \& Jin, R. Experimental and computational investigation of Au25 clusters and $\mathrm{CO}_{2}$ : a unique interaction and enhanced electrocatalytic activity. J. Am. Chem. Soc. 134, 10237-10243 (2012).

18. Zhang, S. et al. Polyethylenimine-enhanced electrocatalytic reduction of $\mathrm{CO}_{2}$ to formate at nitrogen-doped carbon nanomaterials. J. Am. Chem. Soc. 136, 7845-7848 (2014).

19. Sreekanth, N., Nazrulla, M. A., Vineesh, T. V., Sailaja, K. \& Phani, K. L. Metal-free boron-doped graphene for selective electroreduction of carbon dioxide to formic acid/formate. Chem. Commun. 51, 16061-16064 (2015) 
20. Sun, J. et al. Ultra-high quantum yield of graphene quantum dots: aromaticnitrogen doping and photoluminescence mechanism. Part. Part. Syst. Charact. 32, 434-440 (2015).

21. Shen, J. et al. Liquid phase exfoliation of two-dimensional materials by directly probing and matching surface tension components. Nano Lett. 15, 5449-5454 (2015).

22. Sharifi, T., Hu, G., Jia, X. \& Wågberg, T. Formation of active sites for oxygen reduction reactions by transformation of nitrogen functionalities in nitrogen-doped carbon nanotubes. ACS Nano 6, 8904-8912 (2012).

23. Lum, Y. et al. Trace levels of copper in carbon materials show significant electrochemical $\mathrm{CO}_{2}$ reduction activity. ACS Catal. 6, 202-209 (2016).

24. Gong, K., Du, F., Xia, Z., Durstock, M. \& Dai, L. Nitrogen-doped carbon nanotube arrays with high electrocatalytic activity for oxygen reduction. Science 323, 760-764 (2009).

25. Qu, L., Liu, Y., Baek, J.-B. \& Dai, L. Nitrogen-doped graphene as efficient metal-free electrocatalyst for oxygen reduction in fuel cells. ACS Nano 4, 1321-1326 (2010)

26. Zhang, L. \& Xia, Z. Mechanisms of oxygen reduction reaction on nitrogen-doped graphene for fuel cells. J. Phys. Chem. C 115, 11170-11176 (2011).

27. Guo, D. et al. Active sites of nitrogen-doped carbon materials for oxygen reduction reaction clarified using model catalysts. Science 351, 361-365 (2016).

28. Wu, J. et al. Nitrogen-doped graphene with pyridinic dominance as a highly active and stable electrocatalyst for oxygen reduction. ACS Appl. Mater. Interfaces 7, 14763-14769 (2015).

29. Xing, T. et al. Observation of active sites for oxygen reduction reaction on nitrogen-doped multilayer graphene. ACS Nano 8, 6856-6862 (2014).

30. Yu, S. S., Zheng, W. T., Wen, Q. B. \& Jiang, Q. First principle calculations of the electronic properties of nitrogen-doped carbon nanoribbons with zigzag edges. Carbon 46, 537-543 (2008).

31. Li, Y., Zhou, Z., Shen, P. \& Chen, Z. Spin gapless semiconductor - metal - halfmetal properties in nitrogen-doped zigzag graphene nanoribbons. ACS Nano 3, 1952-1958 (2009)

32. Shen, A. et al. Oxygen reduction reaction in a droplet on graphite: direct evidence that the edge is more active than the basal plane. Angew. Chem. Int. Ed. 53, 10804-10808 (2014).

\section{Acknowledgements}

This research is financially supported by SABIC. We acknowledge Dr Mike Wallar at University of South Carolina for the mass spectroscopy measurement.

\section{Author contributions}

J.W. and P.M.A. conceived the idea of catalysis of $\mathrm{CO}_{2}$ reduction. S.M., P.J.A.K. and J.W designed the catalysis measurement experiments. S.M., J.I.G., A.Z.Y. and R.L. performed the electrochemical measurement. B.K. executed the isotopic labeling test. L.Z. carried out the coupling NMR test. J.W. and J.S. synthesized and characterized the catalysts. C.S.T. assisted the TEM characterization. P.M.A., P.J.A.K. and G.D. supervised the experiment work. J.W. wrote the manuscript with the inputs from N.C., I.N.O., J.L. and R.V. All authors discussed the results and commented on the manuscript.

\section{Additional information}

Supplementary Information accompanies this paper at http://www.nature.com/ naturecommunications

Competing financial interests: The authors declare no competing financial interests.

Reprints and permission information is available online at http://npg.nature.com/ reprintsandpermissions/

How to cite this article: $\mathrm{Wu}, \mathrm{J}$. et al. A metal-free electrocatalyst for carbon dioxide reduction to multi-carbon hydrocarbons and oxygenates. Nat. Commun. 7, 13869 doi: $10.1038 /$ ncomms13869 (2016).

Publisher's note: Springer Nature remains neutral with regard to jurisdictional claims in published maps and institutional affiliations.

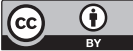

This work is licensed under a Creative Commons Attribution 4.0 International License. The images or other third party material in this article are included in the article's Creative Commons license, unless indicated otherwise in the credit line; if the material is not included under the Creative Commons license, users will need to obtain permission from the license holder to reproduce the material. To view a copy of this license, visit http://creativecommons.org/licenses/by/4.0/

(C) The Author(s) 2016 